\title{
LA RE-CREACIÓN DEL HECHO HISTÓRICO A TRAVÉS DE LA RECONSTRUCCIÓN DE LA ORALIDAD EN JULIUS CAESAR DE WILLIAM SHAKESPEARE
}

\author{
THE RE-CREATION OF THE HISTORICAL FACT THROUGH THE ORAL \\ DECONSTRUCTION IN JULIUS CAESAR OF WILLIAM SHAKESPEARE **
}

\section{Diana Costales Garcia*}

\section{RESUMEN}

El texto analiza el proceso por medio del cual William Shakespeare, en su drama Julius Caesar, parte de las fuentes históricas escritas del asesinato de Julio César, en particular Plutarco y Suetonio, para recrear artísticamente los procesos orales que les dieron origen. También plantea el cuestionamiento sobre lo que constituye el llamado "rigor histórico" de las obras artísticas con este tipo de temática.

Palabras clave: Shakespeare, Julio César, oralidad, escritura, historiografía.

\begin{abstract}
The text discusses the process by which William Shakespeare in his play Julius Caesar, parts from written historical sources of the assassination of Julius Caesar, Plutarch and Suetonius in particular, to recreate artistically oral processes that gave rise to them. It also raises the question of what constitutes the so-called "historical accuracy" of artistic works with this kind of subject.

Key Words: Shakespeare, Julius Caesar, orality, writing, historiography.
\end{abstract}

* Universidad Iberoamericana Ciudad de México, México.

** Traducción: Lic. Geannette Soto. Escuela de Lenguas Modernas, Universidad de Costa Rica.

Correo electrónico: dianacost@yahoo.com

Recepción: 08/01/13. Aceptación: 29/04/13. 


\section{Introducción}

En muchas ocasiones, los relatos orales que se generan alrededor de los acontecimientos de importancia, constituyen la base de las versiones históricas oficiales (por supuesto, escritas) acerca de los mismos. En su obra Julius Caesar, William Shakespeare efectúa el proceso inverso: a partir de los constructos históricos escritos a posteriori, reconstruye y re-crea artísticamente los procesos orales inmediatos al asesinato del dictador, dejando claro, de modo implícito, que éstos influirán tanto en la percepción del hecho como en la manera en que éste será recordado. En este escrito, analizo la representación de dicho proceso en el drama; planteo además el cuestionamiento sobre lo que constituye el llamado "rigor histórico" de las obras artísticas con este tipo de temática.

Mi texto inicia con la cuestión del "rigor histórico"; posteriormente, hace un recorrido general sobre la historiografía romana; continúa con las versiones del asesinato de Julio César según Plutarco y Suetonio, y culmina con el análisis de la representación artística del proceso reconstructivo del hecho histórico, de la oralidad a la escritura.

\section{El "rigor histórico"}

Cuando un historiador se topa con obras literarias basadas en hechos históricos, generalmente critica la falta de rigor histórico que encuentra en ellas. Muchos lectores "profanos" (que no se dedican de lleno ni a las letras ni a la historia), piensan que lo representado en la literatura de base histórica es el hecho histórico tal cual sucedió. En realidad, ninguna de las dos posturas anteriores es la más indicada para acercarse a este tipo de obras.

A partir del surgimiento de la llamada "Nueva Novela Histórica" (siglo XX), los autores literarios han encontrado en la Historia una rica veta para la creación, en la que la veracidad del hecho histórico deja de ser el centro de la escritura para convertirse en un pre-texto a partir del cual se construye una expresión artística enfocada en los aspectos humanos que podemos encontrar en él. Dado que este es el objetivo central de la obra, el autor se toma algunas licencias: matiza, manipula y, en algunos casos, falsea la información que ha tomado de las versiones históricas (oficiales y no oficiales) en aras de su propósito expresivo. Por lo tanto, la matización del hecho histórico se convierte, entonces, en un recurso técnico para lograr cierto efecto en el receptor.

Aunque este fenómeno literario cobró auge hasta el siglo XX, podemos encontrar algunos de estos rasgos en la obra de un dramaturgo inglés de la época isabelina: William Shakespeare, quien, desde su propio contexto sociocultural, re-creó y matizó en muchos de sus dramas ciertos hechos de la historia oficial, resaltando con ello no pocos aspectos de la naturaleza humana y llevando éstos al más alto nivel de la creación poética. Sus obras históricas se centran en dos rubros principales: la historia de Inglaterra (su patria) y los hechos más relevantes de las antiguas Grecia y Roma (lo cual obedece al interés que había en su momento por las culturas clásicas, debido al Renacimiento).

A lo largo de este ensayo, me enfocaré en su obra Julius Caesar, del año 1599. Para los estudiosos de la vida y asesinato de Julio César, las fuentes obligadas son las obras de dos biógrafos del siglo I d.C., uno griego y uno romano: Plutarco y Suetonio. Después de la lectura de estos autores, se encuentran con la obra shakesperiana y el primer "defecto" que resalta para ellos es que el dramaturgo ha matizado, agregado, eliminado o condensado ciertos hechos históricos, por lo que juzgan que la obra no tiene el "rigor histórico" necesario. Pero, ¿en qué consiste realmente el "rigor histórico"? ¿Cómo se construyen las versiones históricas oficiales y en dónde se sustenta la inmovilidad inquebrantable de estas versiones?

A partir de los escritos de Plutarco y Suetonio, se han construido y enriquecido los estudios históricos posteriores sobre el tema. Si nos detenemos a analizar un poco, lo primero que notamos es que ambos escribieron sobre Julio César alrededor de un siglo después de la muerte de éste (por tanto, no son testigos presenciales ni fuentes "primarias"). Además de la distancia 
temporal, encontramos que en estos autores abundan expresiones como "se dice", "muchos opinan", etc.; son reconstrucciones de los hechos derivadas tanto de algunas fuentes escritas como de relatos orales y colectivos que, a lo largo de aproximadamente cien años, se nutrieron de matices que nos hacen dudar de su veracidad absoluta, de su precisión incuestionable. Como es lógico, en estas versiones hay mucho de rumor, de oralidad y, por supuesto, de intervención de los historiadores. De hecho, podemos atrevernos a afirmar que la transmisión oral del acontecimiento dio el primer paso hacia el constructo histórico escrito.

Antes de seguir adelante, debemos concretar algunas características de lo que se entiende bajo el término "rumor", para distinguirlo más fácilmente del "chisme". Aunque ambos son parte de la vida cotidiana, en todos los grupos y ámbitos, la diferencia básica es que el chisme, generalmente, tiene lugar entre grupos específicos y delimitados (gente que se conoce entre sí y que comparte, por ejemplo, una profesión o lugar de trabajo). El rumor es información, cierta o no, que se transmite oralmente, por lo general entre grupos más amplios y en los que la gente que recibe el relato puede no ser ni siquiera cercana a quienes lo protagonizan. Tanto el chisme puede proceder del terreno del rumor como también puede ocurrir lo inverso. Frecuentemente, el rumor es la extensión del chisme hacia áreas o grupos de mayor tamaño.

Tanto uno como el otro laboran encubiertos, fuera de los mecanismos formales de control, por lo que no pueden ser fácilmente verificados. A pesar de ello, pueden causar efectos notorios y, en muchos casos, irreversibles. Una vez sembrados, y aunque después haya una refutación de los hechos, es suficiente para que el relato esparcido se tome como verídico.

En el caso particular del rumor, éste debe ser "liberado" en un contexto ideológico afín a su contenido, para que así pueda germinar. Afirmado por conversaciones y recuerdos colectivos, afirmados sobre presuposiciones y pensamiento interpretativo, dicho contexto ideológico, más que las palabras en sí mismas, es quien en realidad produce los efectos (Stewart 2).

Otro factor importante en la aceptación del rumor es quién lo cuenta (confiabilidad) y cuál es su motivo para hacerlo (venganza, odio, celos, agradecimiento, etc.). Asimismo, el componente emocional también tiene un gran peso: en tiempos de crisis, miedo o amenaza, acciones normalmente consideradas inocentes pueden ser vitas como sospechosas, ya que en estos momentos la gente es más vulnerable y propensa a creer en rumores (como lo vemos en Julius Caesar).

En momentos de crisis, el rumor puede actuar de dos formas: o propaga alarmas infundadas o ayuda a la gente a sobrevivir e incluso a mantener unido al grupo. Hay ambas posibilidades, y el resultado puede ser tanto positivo como negativo; o ambos: positivo para algunos, negativo para otros.

El rumor pasa por tres procesos al transmitirse de persona a persona:

1. El relato se hace cada vez más corto, conciso y fácil de relatar.

2. Retención y narración selectiva (va de la mano con el proceso anterior).

3. Los relatos tienen la tendencia a ser más coherentes y consistentes con las presuposiciones e intereses de quienes los transmiten.

En estos procesos, el rumor no sólo se desvía de los hechos "verídicos" (siempre abordando con prudencia el término) mientras más se traslade sino que, en tanto que lo hace, adquiere, cada vez más, formas narrativas estandarizadas. Con el tiempo, se puede transformar en leyenda, que no es otra cosa que un rumor que ha adquirido una consistencia más sólida.

Las dimensiones del rumor varían en relación con la importancia que el tema tenga para los individuos y la ambigüedad de las evidencias. Ambas cosas son fundamentales en la producción y transmisión de este fenómeno. Frecuentemente, el rumor es una forma de llenar los huecos interpretativos alrededor de los 
hechos y crea narrativas afines con suposiciones, temores o esperanzas de los miembros del grupo, quienes por tendencia natural buscan encontrar sentido a su entorno.

Por tanto, el rumor tiene su génesis en la incompletud de información y en la ansiedad que emana de esta incertidumbre. El rumor no necesariamente parte de la falsedad; gran parte de las veces parte de hechos verídicos que se van matizando y, por ello, está en constante construcción. Sus transformaciones no son sólo distorsiones, sino parte del proceso de llegada a consensos. Una vez que éstos se establecen y se asume el rumor como la versión oficial de los hechos, la escritura contribuye a consolidar dichos relatos como narraciones históricas.

Lo que hace Shakespeare en su Julius Caesar es la operación inversa: a partir de dichos constructos escritos, reconstruye $y$ re-crea tanto los hechos como el proceso de rumor y oralidad que rodeó a las primeras percepciones del asesinato del triunviro romano, enriqueciéndolos con técnicas artísticas que provocan en el lector una reacción estética que en muy pocas ocasiones (a lo largo de siglos y de nuevas versiones que ya incluyen el cine y la televisión) se ha podido igualar.

Para este análisis, seguiré los siguientes pasos: primero explicaré lo que la Historia significaba para los romanos de la época, ya que su historiografía es la base de las construcciones posteriores; después abordaré las versiones de Plutarco y Suetonio, resaltando las huellas orales que se han filtrado en ellas; finalmente, abordaré la obra de Shakespeare.

\section{La historiografía romana}

El tema principal de la Historia en la Antigua Roma era la política. Los nobles disfrutaban de cantos poéticos que narraran los hechos heroicos de sus antepasados, y los anales (aparecidos hacia el siglo III a.C.) guardaban registro de los sucesos importantes. En cuanto a las leyendas y mitos sobre sus orígenes, aparecieron tardíamente e inspirados por la mitología griega.

El romano, de tendencia práctica, pretendía justificar a través de la Historia la grandeza de su patria. Los historiadores fueron apoyo de estadistas y oradores que buscaban sustentar la legitimidad de sus acciones y discursos. Sus narraciones (que contaban con un estilo elegante) tenían como fin principal coronar a Roma como la cumbre del devenir de la humanidad.

Este empeño tan político, que limitó muchos
aspectos de la historiografía hacía, sin embargo,
que el héroe de las hazañas fueran no ya los
personajes particulares, sino el pueblo romano en
anónimo (Vázquez de Knauth, 1973: 31).

Hacia el siglo I a.C. -la época en la que vivió Julio César (101-44 a.C.)-, ante la tensión generada por los conflictos personalistas y el fin de la república como se le había conocido hasta entonces, surge el relato historiográfico que ya no se enfoca en rastrear los acontecimientos hasta los orígenes ni permanece como género "anónimo"; sino que se interesa en una época, hecho o personaje particular: el mismo Julio César ejerció como historiador (destacándose a sí mismo) en sus Comentarios a la Guerra de las Galias y los Comentarios a las Guerras Civiles.

Salustio (87-37 a.C.) afirmaba que el objetivo de la Historia era conservar la memoria de los hombres virtuosos que sirvieran de ejemplo a la sociedad. Asimismo, Marco Tulio Cicerón (106-43 a.C.) consideraba que la Historia era "testigo de los tiempos, luz de la verdad, vida de la memoria, maestra de la vida, mensajera de la Antigüedad" (Vázquez de Knauth 1973: 33). Se lamentaba de que la historiografía se perdiera tantas veces en la elocuencia y defendía la idea utópica de que en la Historia no debe haber nunca falsedad, ocultamiento ni pasión. Para él, su utilidad era muy clara: enriquecer y sustentar un discurso.

Durante el siglo posterior a la muerte de César, la Historia era fuente de educación patriótica y cívica. Para Tito Livio (59 a. C.-17 d.C.) importaba no tanto la "verdad absoluta", sino la "verdad útil" como enseñanza. Esto, 
por supuesto, se prestaba a manipulaciones de los hechos históricos. Contemporáneos de Tito Livio, Plutarco (46?-120 d.C.) y Suetonio (75-160 d.C.) viven inmersos en este concepto de la historiografía. Para el tema que nos ocupa, es importante recordar que muchos documentos y anales se perdieron durante el gran incendio del año 64 d.C, atribuido al emperador Nerón, con lo que se perdió una gran cantidad de información valiosa. Por lo tanto, las fuentes de estos biógrafos deben haber incluido tanto escritos sobrevivientes al incendio, como narraciones transmitidas oralmente de generación en generación.

Aun así, debemos distinguir entre el género propiamente historiográfico del biográfico, a fin de comprender mejor a las dos fuentes principales del drama de Shakespeare. Tanto los griegos como los romanos mantenían a la biografía un tanto separada de la Historia. Esto le permitía a la primera conservar lo que cada rey o personaje importante poseía de humano.

La biografía brindaba mayor libertad al autor. De por sí, también el concepto de Historia estaba regido por una noción de "verdad" que no es muy cercana a la necesidad de exactitud en los hechos; más bien, dependía de la intención y finalidad del relato, así como del público al que iba dirigido (no tan distinto, en este aspecto, a las versiones históricas oficiales contemporáneas). Esta libertad le permitía al autor un más amplio margen de imaginación que en las biografías actuales. En aquellas sociedades, la biografía se enfocaba, más que en una precisión rigurosa, en anécdotas así como en aspectos morales y cotidianos del personaje en cuestión.

La biografía antigua es la base de lo que se conoce como historiografía ensayística de época imperial. Dicha biografía tenía un carácter basado principalmente en aspectos morales: a través de la vida de una persona, se buscaba expresar una cierta ética. La mayoría de las veces se usaba para dar un ejemplo positivo, aunque también se utilizaba para el caso opuesto. En este sentido, historia y biografía son muy cercanas una a otra; incluso, llegaron a confundirse ambos géneros como si fueran sinónimos. Sin embargo, en la técnica es donde se aprecian mejor las diferencias.

\begin{abstract}
Normalmente, en la biografía el personaje suele ser caracterizado a partir de unos hechos y de unos dichos que la tradición le atribuye -a él o a otro: las mezclas y confusiones son numerosas, sin que importe demasiado ya que se trata, en esta caracterización de un personaje, de lo que el autor quiere poner de relieve, para su propio interés, el interés de lo que quiera exponer. (Mestre, Francesca. Consultado en línea)
\end{abstract}

\section{Las versiones de Plutarco y Suetonio}

Durante el dominio romano en Grecia, los griegos se adaptaron a la nueva relación política con Roma, pero se dedicaron a fijar aun más su identidad dentro de la nueva situación. Plutarco fue uno de estos ciudadanos griegos/romanos.

Nacido en Queronea, cerca de Delfos. En su obra, busca el paralelo entre las civilizaciones griega y romana. De ahí la estructura de sus Vidas paralelas: la vida de un griego junto a la de un romano, seguidos de una comparación. Busca, de esta forma, puntos de convergencia entre ambas culturas. Rescata lo griego sobre lo romano, a fin de que Roma viera a Grecia en términos de cooperación más que de la relación conquistadorconquistado. Sus biografías eran, pues,

una forma de salvar la propia identidad del grupo a base de la integración, hasta un cierto punto, del otro en lo propio (Mestre, Francesca. Consultado en línea).

La biografía griega ejerce un papel fundamental en el origen y desarrollo del género en Roma, en el cual se puede distinguir, sobre todo, la influencia de tres tendencias:

el encomion (alabanza de personajes famosos), la
biografía de la escuela peripatética (estilo biográfico
más objetivo, que insiste en el análisis del género de
vida y en los caracteres de los personajes) y la de
la época helenística, de carácter erudito (Morano
Rodríguez, Ciriaca. Consultado en línea).

Por su parte, el romano Suetonio (Gaius Sutonius Tranquillus), nacido en Hipona, vive 
en un contexto cultural que se nutre de imitar a los antiguos, así como de la erudición de éstos. Puede ser considerado como un historiador ya que es minucioso en sus investigaciones y afecto a la revisión de documentos. Nombrado secretario de la correspondencia oficial ( $a b$ epistulis) por el emperador Adriano, tiene acceso a los archivos y a la correspondencia de Julio César y de Augusto, lo que le resulta de gran ayuda en la configuración de sus biografías y relatos históricos. Al igual que otros historiadores y biógrafos de su época, se centra más en anécdotas que en hechos considerados relevantes desde el punto de vista de la historiografía contemporánea. No procede por orden cronológico sino por categorías temáticas como estirpe, vida militar, vida privada, etc.

En lo que concierne al caso particular de la vida y muerte de Julio César, ni Plutarco ni Suetonio especifican cuáles fueron sus fuentes escritas (no existía la obligación académica actual de citar por escrito las fuentes de investigación); sin embargo, es indudable que contaron con ellas. Aun así, en sus biografías y relaciones del asesinato, encontramos muchas expresiones que nos remiten al funcionamiento del rumor: "se dice", "opinan", "parece que", etc. La oralidad y el rumor, en el caso del asesinato de una figura política, son las primeras fuerzas modeladoras de la opinión pública, así como de la percepción de quienes viven de cerca el acontecimiento (los testimonios presenciales son, en primera instancia, orales y diversos). Esto sienta las bases de la recepción global del hecho y, por lo tanto, influye grandemente en lo que después se oficializará y perdurará en los textos escritos.

A continuación, abordaremos rápidamente a cada uno de estos biógrafos por separado:

Plutarco incluye la vida de Julio César en su obra Vidas paralelas. En ocasiones, toma preferencia por alguna de las versiones que rescata; por ejemplo, cuando refiere que César enojó a los senadores al no levantarse ante ellos, escribe:

Después se excusó de lo pasado con su enfermedad, diciendo que el sentido de los que la padecían no puede estar en su asiento cuando les es preciso hablar de pie a la muchedumbre, sino que fácilmente se conmueve y altera, padeciendo vértigos, y estando expuestos a quedarse privados; pero esto no fue así, sino que queriendo César levantarse al Senado, se refiere haber sido detenido por Cornelio Balbo, uno de sus amigos, o por mejor decir de sus aduladores, quien le dijo: “¿No te acordarás de que eres César? ¿Ni dejarás que te respeten como corresponde a quien vale más que ellos?" (Plutarco 1999: 285, subrayado mío)

Otras veces, asume que no es posible saber con certeza absoluta el modo en que ocurrieron los sucesos; por ello, se conforma con señalar los distintos relatos existentes sin comprometerse explícitamente con ninguno: "A lo que parece, no fue tan inesperado como poco precavido el hado de César: porque se dice haber precedido maravillosas señales y prodigios. [...] Todavía hay muchos de quienes se puede oír que un agorero le anunció aguardarle un gran peligro en el día del mes de marzo que los romanos llamaban los Idus" (Plutarco 1999: 286, subrayado mío).

Por su parte, Suetonio sirvió al emperador Adriano en sus archivos, lo que le dio acceso a documentos. En Los doce césares, se centra en cada uno de los emperadores a quienes retrata, y se entretiene también en detalles y anécdotas de su cotidianidad, cuyo origen es, muy seguramente, oral.

La importancia de Suetonio estriba en que ha tenido posteriormente mucha influencia; representa el tipo de escritor que intenta divertir, aun a costa de la insistencia en toda clase de relatos desagradables. Los emperadores resultan un buen tema; no se enjuician ni su actuación ni su importancia, pero sabemos cómo eran físicamente, cuáles eran sus debilidades y costumbres, su grado de religiosidad, sus gustos, cuántos monumentos inauguraron y cuántas fiestas dieron para fomentar su popularidad entre la plebe. Escritor ya de una época de decadencia, insiste precisamente en los hechos con que los emperadores impresionaban al pueblo (Vázquez de Knauth, 1973: 40).

Al igual que Plutarco, Suetonio rara vez es tajante en sus afirmaciones y juicios; por el contrario, tiene la prudencia de adjudicar a otros (sin especificar) la mayor parte de las narraciones: "Impútansele, sin embargo, acciones 
y palabras que demuestran el abuso del poder y que parecen justificar su muerte" (Suetonio 1985: 51). También en su obra encontramos huellas de los relatos orales y rumores:

\begin{abstract}
Sobre este asunto propagóse un rumor que adquirió bastante consistencia, asegurándose que pensaba trasladar a Alejandría o a Troya la capital y fuerzas del Imperio, [...] añadiéndose que en la primera reunión del Senado el quindecimviro L. Cotta debía proponer que se diese a César el título de rey" (Suetonio, 1985: 53).
\end{abstract}

Conviene aquí detenernos para explicar cabalmente la naturaleza y el comportamiento del rumor.

Margarita Zires Roldán, en su artículo "Las dimensiones del rumor: oral, colectiva y anónima", publicado por la Universidad Autónoma Metropolitana, afirma, de entrada, que el rumor "no se comporta como un texto escrito" (1991: 23). A pesar de que en la cultura contemporánea se le percibe de una forma peyorativa dada la imprecisión de su discurso, siempre ha sido fundamental en el devenir de un grupo social: otorga a éste cohesión y a sus miembros, sentido de pertenencia.

El rumor, como toda comunicación oral, se complementa con signos tanto paralingüísticos (tono de voz, volumen) como quinésicos (lenguaje corporal), los cuales le confieren una dimensión teatral. Esto y otras condiciones, como la necesidad de la presencia física de los interlocutores y la simultaneidad de varios niveles de percepción sensorial, convierten a la comunicación oral en "un proceso de negociación en el que los participantes están permanentemente definiendo y redefiniendo la situación comunicativa (el marco o encuadre de la interacción, el framing)" (1991: 25). Por lo tanto, va mucho más allá de simple transmisión de información, ya que abarca no sólo a varios interlocutores, sino a múltiples situaciones de interacción que van reproduciendo y a la vez transformando un relato. Por lo tanto, el rumor tiene una función triple: oral, colectiva y anónima, ya que es imposible guardar registro del responsable de cada matiz.

Las fuentes biográficas que hemos mencionado se basan en textos escritos anteriores, así como en rumores y testimonios orales; obviamente, es de esperarse que los acontecimientos hayan sido transfigurados a lo largo del tiempo, a la vez que se configuraban las versiones históricas "oficiales" (o, por lo menos, más conocidas) del asesinato de Julio César.

Todo esto es suficiente para renunciar a la idea de "veracidad absoluta" en lo que concierne a la historiografía de estos hechos. La recreación dramática hecha por Shakespeare es una matización más de éstos, pero obedece a una finalidad distinta: la creación artística.

\section{Julius Caesar de William Shakespeare}

Shakespeare se basó e inspiró mayormente en los escritos de Suetonio y Plutarco. También, aunque en menor medida, en los de Lucano y Cicerón. Éste y Séneca, entre otros, rescatan la figura de Marco Bruto, resaltando su lealtad, bondad, honradez e integridad (Quevedo, 1950: 13-14).

El dramaturgo inglés se hace eco de estas voces y nos presenta a un Marco Bruto que se erige en héroe trágico de la obra; dentro de ésta, él es el único que asesina a César no por envidia ni poder, sino por llevar hasta las últimas consecuencias su concepto de la democracia.

\footnotetext{
Con angustia se da cuenta de que todo acto para alcanzar la libertad y la justicia, fatalmente necesita matar algo en el hombre, quizá... matar al hombre mismo. ¡Horrible destino! ¡Bañar con sangre humana el acto liberador para los humanos! (Nota preliminar de la edición de Porrúa, 2006: 139).
}

A diferencia del resto de los conspiradores, para Bruto la muerte de su padre adoptivo no es otra cosa que un sacrificio que se ofrecerá para lograr un bien mayor: la liberación de los romanos del yugo de la tiranía. Su virtud lo lleva a rehusar matar a Marco Antonio junto con César, por ser la mano derecha de éste: craso error que, a la larga, le cuesta la pérdida de su reputación ante el pueblo y, eventualmente, la vida misma. 
Según Suetonio, el número de conspiradores era superior a sesenta, con Casio y Décimo Bruto (llamado Decio Bruto en el drama) como líderes, de los que Shakespeare nos presenta sólo alrededor de diez. También nos refiere los prodigios que presagiaron eventos negativos poco antes del asesinato. Entre ellos, el adivino Spurinna le advierte al dictador, durante un sacrificio, que se cuide en los Idus de marzo, así como la seguridad de César una vez llegada la fecha:

\begin{abstract}
entró en el Senado y dijo burlándose a Spurinna que eran falsas sus predicciones porque habían llegado los idus de marzo sin traer ninguna desgracia, contestando éste que sí habían llegado, pero aún no habían pasado (Suetonio, 1985: 55).
\end{abstract}

Plutarco refiere también este hecho, sólo que sin especificar el nombre del adivino ni la situación en que fue hecha la profecía. Nos relata que César

saludó al agorero y como por burla le dijo: "Ya han llegado los idus de marzo"; a lo que le contestó con gran reposo: "Han llegado, sí, pero no han pasado" (Plutarco, 1999: 286).

Shakespeare, sin decir tampoco el nombre del adivino, recrea estos acontecimientos distanciándolos uno del otro en la estructura del drama, a diferencia de los historiadores, quienes los narran poniéndolos casi inmediatamente uno después del otro. En Julius Caesar, la predicción tiene lugar en el acto primero (las traducciones al español del texto de Shakespeare son de la investigadora):

Soothsayer: Caesar!

Caesar: Who calls?

Casca: Bid every noise be still: peace yet again! Caesar: Who is it in the press that calls on me? I hear a tongue, shriller than all the music,

Cry 'Caesar!' Speak; Caesar is turn'd to hear. Soothsayer: Beware the ides of March.

Caesar: What man is that?

Brutus: A soothsayer bids you beware the ides of March.

Caesar: Set him before me; let me see his face. Casca: Fellow, come from the throng; look upon Caesar.
Caesar: What say'st thou to me now? Speak once again.

Soothsayer: Beware the ides of March.

Caesar: He is a dreamer; let us leave him: pass. (Act I, Scene II, 12-24)

Adivino: ¡César!

César: ¿Quién me llama?

Casca: Que cese todo ruido:jsilencio de nuevo!

César: ¿Quién, entre la multitud, me llama?

Oigo una voz, más aguda que toda la música,

Clamar '¡César!' Hablad; César se vuelve a oíros.

Adivino: Cuidado con los idus de Marzo.

César: ¿Qué hombre es ése?

Bruto: Un adivino os dice que os cuidéis de los idus de Marzo.

César: Traedlo ante mí; dejadme ver su rostro.

Casca: Mozo, salid del gentío; mirad a César.

César: ¿Qué me decís ahora? Hablad una vez más.

Adivino: Cuidado con los idus de Marzo.

César: Es un soñador; dejémoslo: abrid paso.

(Acto I, Escena II, 12-24)

La burla de César al adivino y la respuesta de éste ocurren justo al inicio del tercer acto, que corresponde al clímax de la obra:

Caesar: [To the Soothsayer] The ides of March are come.

Soothsayer: Ay, Caesar; but not gone.

(Act III, Scene I, 1-2)

César: [Al Adivino] Los idus de Marzo han llegado.

Adivino: Sí, Caesar; pero no se han ido.

(Acto III, Escena I, 1-2)

La distancia estructural entre ambos acontecimientos, así como la intercalación entre ellos de la conspiración, las dudas de Bruto y los presagios fatídicos, afectan la recepción de estos hechos por el lector/espectador: llegado este acto climático, la tensión ha ido en aumento y la expectativa es la idónea para que el asesinato sea presenciado con una mayor intensidad.

Ambos biógrafos coinciden en la esencia de la dinámica del crimen: alguien entretiene a Marco Antonio (Plutarco adjudica esta misión a Bruto Albino; Shakespeare, a Trebonio) y los conspiradores se acercan a César con el pretexto de hacerle humildemente una petición antes de 
apuñalarlo veintitrés veces; los movimientos del triunviro al ser atacado, así como su posición al caer, también son narrados en detalle y de manera muy similar en las dos fuentes históricas. Suetonio relata que, al ver a Bruto entre los conspiradores, pronunció las famosas palabras que ya han pasado a la Historia: “¡Tú también, hijo mío!” (Suetonio 1985: 55). Plutarco refiere que cayó a los pies de la estatua de su otrora rival, Pompeyo. Shakespeare ( $\mathrm{sin}$ detenerse a representar los detalles de los movimientos de César) toma ambos elementos en la construcción de su drama:

Casca: Speak, hands, for me!

[Casca first, then the other Conspirators and Marcus Brutus stab Caesar.]

Caesar: Et tu, Brute! Then fall, Caesar! [Dies.]

Cinna: Liberty! Freedom! Tyranny is dead!

Run hence, proclaim, cry it about the streets.

\section{[...]}

Brutus: How many times shall Caesar bleed in sport,

That now on Pompey's basis dies along

No worthier than the dust!

(Act III, Scene I, 76-79, 114-116)

Casca: ¡Hablad, manos, por mí!

[Casca, luego los otros Conspiradores y Marco Bruto apuñalan a César.]

César: ¡Y tú, Bruto! ¡Muere entonces, César! [Muere.]

Cinna: ¡Libertad! ¡Libertad! ¡La tiranía ha muerto!

Corred, proclamad, pregonadlo por las calles.

\section{[...]}

Bruto: ¡Cuántas veces sangrará en los juegos César,

Que ahora yace al pie de la base de Pompeyo

No más valioso que el polvo!

(Acto III, Escena I, 76-79, 114-116)

También pone en labios de Cinna los gritos de gozo que Plutarco atribuye a todos los conspiradores, incluyendo a Bruto, después del asesinato.

Por otra parte, Plutarco y Suetonio coinciden en que el funeral de César, la lectura de su testamento frente al pueblo y la intención de éste de linchar a los conspiradores ocurrieron al día siguiente del atentado. Shakespeare condensa estos hechos como inmediatos al asesinato, intercalando los discursos de Bruto y Marco Antonio. Esto es una licencia que se da a sí mismo, en aras de aumentar la tensión dramática de su argumento.

Lo que es digno de destacar, es que ni Suetonio ni Plutarco mencionan que Marco Antonio haya pronunciado el discurso que provocó que el pueblo romano se levantara dispuesto a linchar a los conspiradores. Plutarco menciona:

\begin{abstract}
Abrióse el testamento de César, y se encontró que a cada uno de los ciudadanos romanos dejaba un legado de bastante entidad: con esto, y con haber visto el cadáver cuando lo pasaban por la plaza despedazado con tantas heridas, ya la muchedumbre no guardó orden ni concierto, sino que recogiendo por la plaza escaños, celosías y mesas, hicieron una hoguera y poniendo sobre ella el cadáver, lo quemaron. Tomaron después tizones encendidos y fueron corriendo a dar fuego a las casas de los matadores (1999: 288-289).
\end{abstract}

Suetonio, por su parte, cuenta:

En vez de elogio fúnebre, el cónsul Antonio hizo que leyese un heraldo los senatus-consulto que otorgaban a César todos los honores divinos y humanos, y además el juramento que obligaba a todos por la salud de uno, añadiendo por parte suya muy pocas palabras [...]; mas de pronto, dos hombres, que llevaban espada al cinto y dos dardos en la mano, le prendieron fuego con antorchas, y en seguida todos comenzaron a arrojar leña seca, las sillas de las tribunas de los magistrados y cuanto se encontraba al alcance de la mano (1985: 56-57).

Es quizá este relato lo que aprovecha Shakespeare para convertir (de una forma estupenda) la pequeña intervención de Marco Antonio en el manipulador discurso político que exacerba las pasiones vengativas de los romanos.

Las palabras pronunciadas por Bruto ante la multitud no aparecen tampoco en ninguno de los dos autores. Pero Shakespeare las construye y contrasta con las de Marco Antonio para resaltar la diferencia entre la mentalidad ingenua del idealista con la mentalidad ágil y maliciosa del político; lo que más impresiona al receptor es el poder que adquiere la palabra cuando es 
hábilmente manejada por las estrategias de un orador elocuente.

Ambas exposiciones son claros ejemplos del modo en que la oralidad se convierte en el primer vehículo de transmisión de información acerca de lo acontecido. Cada uno de ellos impacta de manera diferente en la opinión del vulgo y genera consecuencias a futuro.

El discurso de Bruto es honesto; tiene un estilo bello, que transmite sensibilidad y realiza juegos de palabras para expresar de manera impactante sus propios sentimientos, así como sus razones para asesinar a César:

If then that friend demand why Brutus rose against Caesar, this is my answer:

Not that I loved Caesar less, but that I loved Rome more. [...] As Caesar loved me, I weep for him; as he was fortunate, I rejoice at it; as he was valiant, I honour him: but, as he was ambitious, I slew him. There is tears for his love; joy for his fortune; honour for his valour; and death for his ambition.

(Act III, Scene II, 18-19, 22-27).

Si entonces aquel amigo pregunta por qué Bruto se levantó contra César, esta es mi respuesta:

No porque amara menos a César, sino porque amaba más a Roma. [...] Porque César me amó, lloro por él; de que fue afortunado, me regocijo; porque fue valiente, le honro: pero, porque fue ambicioso, lo maté. Hay lágrimas para su amor; gozo para su fortuna; honra para su valor; y muerte para su ambición.

(Acto III, Escena II, 18-19, 22-27).

Si bien el discurso es franco y emotivo, carece completamente de malicia. De momento se granjea a los oyentes, quienes lo aclaman como libertador.

Sin embargo, comete el error (o la ingenuidad) de dejar solo a Marco Antonio con la multitud para que también le dirija unas palabras. Éste aprovecha la oportunidad para invertir el ánimo del pueblo. Con una retórica ingeniosa y hábil, su discurso está repleto de lo que actualmente se conoce como "psicología inversa": dice que no pretende hacer lo que en realidad sí está en sus propósitos para, de esta manera, lograrlo con mayor seguridad. Podemos observar este recurso en frases como: "I come to bury Caesar, not to praise him" (Act III, Scene II, 79): "Vine a enterrar a César, no a ensalzarlo" (Acto III, Escena II, 79); "I speak not to disaprove what Brutus spoke,/But here I am to speak what I do know" (Act III, Scene II, 105-106): "No hablo para desaprobar lo que habló Bruto,/Sino que estoy aquí para hablar lo que sé" (Acto III, Escena II, 105-106); "let me not stir you up/To such a sudden flood of mutiny" (Act III, Scene II, 214-215): "no me dejéis agitaros/A tal torrente repentino de revuelta" (Acto III, Escena II, 214215); "I come not, friends, to steal away, to steal away your hearts: I am no orator, as Brutus is" (Act III, Scene II, 220-221): "No vengo, amigos, a cautivar, a robar sus corazones: no soy orador, como lo es Bruto" (Acto III, Escena II, 220-221).

Otro de sus recursos es la ironía, al pronunciar repetidas veces, variando el contexto entre una y otra, "And Brutus is an honourable man" ("y Bruto es un hombre honorable"): lo que inicia sonando a defensa y halago, termina sonando a insulto y descrédito; de tal manera, exacerba el odio del pueblo e incita el deseo de éste de matarlo para vengar a César:

For Brutus is an honourable man;

So are they all, all honourable men-

Come I to speak in Caesar's funeral.

He was my friend, faithful and just to me:

But Brutus says he was ambitious;

And Brutus is an honourable man.

He hath brought many captives home to Rome

Whose ransoms did the general coffers fill:

Did this in Caesar seem ambitious?

When that the poor have cried, Caesar hath wept: Ambition should be made of sterner stuff:

Yet Brutus says he was ambitious;

And Brutus is an honourable man.

(Act III, Scene II, 87-99).

Porque Bruto es un hombre honorable;

Como son todos ellos, todos hombres honorablesVengo yo a hablar en el funeral de César.

Él fue mi amigo, fiel y justo conmigo:

Pero Bruto dice que era ambicioso;

Y Bruto es un hombre honorable. 
Él ha traído muchos cautivos a Roma

Cuyos rescates llenaron las arcas públicas:

¿Pareció esto ambicioso en César?

Cuando los pobres han llorado, César ha llorado:

La ambición debe estar hecha de materia más dura:

Pero Bruto dice que era ambicioso;

Y Bruto es un hombre honorable.

(Acto III, Escena II, 87-99).

Marco Antonio entra en una dinámica de "estira y afloja", al mostrar el testamento del dictador para, inmediatamente, negarse a leerlo frente a todos: "I must not read it;/It is not meet you know how Caesar loved you" (Act III, Scene II, 145146): "No debo leerlo;/No es para que vosotros sepáis cómo César os amó" (Acto III, Escena II, 145-146). Esto sólo aviva la curiosidad y el deseo del pueblo de que el testamento sea leído. Cuando por fin les dice su contenido (que César ha nombrado herederos a sus ciudadanos), el ánimo popular ya está preparado para reaccionar como Antonio quiere: se inicia una revuelta encaminada a linchar a los conspiradores y ensalzar cada vez más la memoria del difunto. Al ocurrir esto, Marco Antonio (quien antes pronunció palabras que intentaban disuadir a la gente de su intento) lo celebra consigo mismo: "Now let it work. Mischief, thou art afoot,/Take thou what course thou wilt!" (Act III, Scene II, 265-266): "Ahora dejémoslo trabajar. Revuelta, estáis en marcha,/¡Tomad el curso que deseéis!" (Acto III, Escena II, 265-266).

Todo este discurso echa mano del recurso retórico que se conoce como amplificatio (amplificación), que se basa más en la movilidad de los afectos que en las argumentaciones. Como dice Perla Chinchilla Pawling:

Decir lo mismo de modo diferente, variar la forma y no el contenido, eso es amplificar, y el resultado comunicativo es persuadir al otro de la "verdad" de la enunciación a través del movimiento de los afectos. No hay aumento de información, sino confirmación de la información original. El "flujo rapsódico del discurso oral" corre sin poder regresar sobre lo dicho, su virtud no es la de la precisión y la exactitud, sino la de la verbosidad y la copia, no se presta para el análisis ni la argumentación lógica" (Garay, 2007: 39).
Este tipo de recurso funciona mejor en la oralidad que en la escritura, ya que ésta brinda al receptor la oportunidad de volver al discurso y analizarlo con más detenimiento; de esta forma, crece la posibilidad de detectar y concientizar las técnicas manipulativas de persuasión. En cambio, las características del lenguaje oral (su simultaneidad con la situación y su falta de registro exacto una vez finalizado) impiden o, por lo menos, limitan ese proceso de análisis. En Julius Caesar, esto es aprovechado por Marco Antonio. Al leer el drama, podemos inferir que al unir sus recursos retóricos con los signos paralingüísticos y quinésicos que introducen su discurso en la esfera de lo teatral, consigue mover los afectos de los oyentes y convencerlos de lo que quiere. (En la representación de la obra, esto tiene un gran impacto en el espectador si Marco Antonio es interpretado por un buen actor y bajo una buena dirección de escena.)

Por razones obvias, es el discurso de Marco Antonio el que surte más efecto en el pueblo romano. La reputación destruida de Bruto y del resto de los conspiradores, ayuda a que Octavio (sobrino y heredero de César) acceda al trono prácticamente sin resistencias. Del mismo modo, marca para siempre la suerte de los asesinos, quienes deben exiliarse y luchar contra el nuevo Triunvirato con una clara desventaja.

Plutarco atribuye a la justicia divina la derrota y muerte de los conspiradores; para él, es una señal de desaprobación de los dioses por el crimen cometido. Suetonio cuenta que ninguno de ellos sobrevivió más de tres años ni murió por causas naturales, pero no da su propia opinión al respecto. Shakespeare, en cambio, de acuerdo con la cosmovisión de su época, atribuye estos hechos a lo que conocemos como "fatal flaw" (defecto o error fatal): en el caso de Bruto, consiste en su ingenuidad y en el ejercicio trágico de su virtud (que le lleva a perdonar la vida a Marco Antonio, a cometer errores de graves consecuencias y, al final, al sentimiento de culpa y al dolor por haber asesinado a su padre adoptivo sin lograr para Roma la libertad buscada); en cuanto a Casio, el "fatal flaw" se centra en su envidia hacia las figuras poderosas, acompañada por un carácter impulsivo que lo precipita a suicidarse por el malentendido de 
creer perdida una batalla que se ha ganado. En conclusión, Shakespeare atribuye los desenlaces trágicos a errores humanos, no al Destino ni a una divinidad arbitraria.

\section{Conclusión}

Fuera de la obra Julius Caesar, en el devenir historiográfico la balanza se ha inclinado tanto a favor de Bruto como de Julio César, dependiendo del contexto y de la "voz" (en sentido amplio) que reactualice el relato histórico. Todo está en función de quién, cómo, en qué condiciones, sobre qué bases y con qué intereses se haga la narración. Hasta la fecha, más de dos milenios después, hay quienes defienden la honradez de Bruto y quienes lo atacan por traidor, al igual que a Julio César se le ha calificado de hombre ilustre y de tirano. Sin embargo, no podemos negar que en estas percepciones han influido los registros históricos que comenzaron a escribirse desde la misma época del asesinato y de los que pocos sobreviven; pero estos registros, como ya hemos explicado, parten en gran medida de rumores, de memoria colectiva y de relatos orales de quienes vivieron de cerca el acontecimiento.

A lo largo de este trabajo, hemos visto que Shakespeare, en Julius Caesar, reconstruye el proceso de formación de los relatos que, en algún momento, constituirán las versiones históricas oficiales sobre el asesinato del triunviro, así como sobre la conspiración previa y los acontecimientos posteriores. La oralidad de los rumores y testimonios presenciales marca el inicio de la configuración de las narraciones que en un futuro se oficializarán en las versiones escritas. De este modo, se empiezan a estructurar las biografías y relatos históricos que condicionarán las posteriores percepción, memoria y representación de los acontecimientos. Leer el drama de Shakespeare (o acudir a verlo en el teatro) desde esta perspectiva, nos hace cuestionar lo comúnmente considerado como "rigor histórico" (fidelidad a los hechos tal cual sucedieron) así como concienciar la influencia de los relatos orales en los constructos históricos que serán fijados por la escritura. Shakespeare reconstruye y recrea de manera magistral este proceso primigenio basado en la elaboración del discurso oral, matizando el hecho histórico de una manera que resalta, como toda obra de arte, las inclinaciones y pasiones humanas; todo ello con verosimilitud, emotividad y, sobre todo, talento artístico.

\section{Bibliografía}

Chinchilla Pawling, Perla. 2007. "Oralidad y escritura”. En: Garay (coord.): 33-50.

Garay, Graciela de (coord.). 2007. Para pensar el tiempo presente. Aproximaciones teóricometodológicas y experiencias empíricas. México: Instituto Mora.

George Clark, William and William Aldis Wright (ed.). 1864. The Complete Works of William Shakespeare. With the Complete Temple Notes by Israel Gollancz. New York: Grosset \& Dunlap.

Mestre, Francesca. "Plutarco y la biografía en época imperial". Revista de Estudios Clásicos. Universidad Nacional de Cuyo. Instituto de Lenguas y Literaturas Clásicas. 2007. Web. http://bdigital.uncu.edu.ar/ objetos_digitales/2658/mestreplutarco.pdf

Morano Rodríguez, Ciriaca. "Historiografía latina". Sociedad Española de Estudios Clásicos. 1979. Web. http://interclassica. u m.es/index.php/interclassica/ investigacion/hemeroteca/e/estudios clasicos/numero_83_1979/historiografia_ latina

Plutarco. 1999. "Cayo Julio César". Vidas paralelas. México: Porrúa. "Sepan Cuantos...”, Núm. 26: 256-290.

Quevedo, Francisco de. 1950. "Juicio que de Marco Bruto hicieron los autores en sus 
obras". Vida de Marco Bruto. [1644]. Buenos Aires-México: Espasa-Calpe Argentina: 13-17.

Shakespeare, William. Julius Caesar. [1599]. En: Clark and Wright (ed.): 949-978. 2006. "Julio César". México: Porrúa. “Sepan Cuantos...” Núm. 96: 139-185.

Stewart, Pamela J. "Rumor and Gossip. An Overview". Witchcraft, Sorcery, Rumors and Gossip. Cambridge University Press. Web. http://site.ebrary.com/ id/10120485?ppg $=47$
Suetonio. 1985. "Cayo Julio César". Los doce césares. México: SEP Cultura: 9-58.

Vázquez de Knauth, Josefina. 1973. "II. Historiografía romana". Historia de la historiografía. $2^{a}$ ed. México: SEP/ SETENTAS: $30-41$.

Zires Roldán, Margarita. 1991. "Las dimensiones del rumor: oral, colectiva y anónima". México: Universidad Autónoma Metropolitana. Consultado el 30 de noviembre de 2010: 1-29. <http://www. lacult.org/docc/oralidad_08_23-29-lasdimensiones-del-rumor.pdf $>$ 
